\title{
Pain relief by extracorporeal shockwave therapy: an update on the current understanding
}

\author{
Christoph Schmitz $\cdot$ Rocco DePace
}

Received: 2 November 2008 / Accepted: 24 April 2009 / Published online: 15 May 2009

(C) The Author(s) 2009. This article is published with open access at Springerlink.com

\section{To the Editor}

We have read with great interest the hypothesis article written by Dr. O. Wess concerning "A neural model for chronic pain and pain relief by extracorporeal shock wave treatment" (ESWT) published recently in Urological Research [1]. We would like to express to the readers of Urological Research our concerns about the content and concept of this article.

We believe, a clear warning should be expressed to your readership. On page 328 of his article, Dr. Wess [1] states "This treatment regime or a similar one is used for chronic pelvic pain as well as shoulder pain, heel spur and angina pectoris for example." This statement is made without any reference and might imply to readers that ESWT is an equally accepted treatment modality for these very different indications. However, this is not the case.

ESWT has become a well-established treatment opportunity for several diseases of the musculoskeletal system such as chronic plantar fasciitis [2, 3], chronic Achilles tendinopathy [4-6] and chronic lateral epicondylitis ("tennis ellbow"; [7-9]). On the other hand, experience with ESWT as a treatment regime for chronic pelvic pain syndrome or angina pectoris can be regarded only experimentally to date $[10,11]$, or for that matter, anecdotally. The casual use of ESWT in the treatment of angina pectoris could result in

C. Schmitz ( $\square)$

EMS Electro Medical Systems, Ch. de la Vuarpillière 31,

1260 Nyon, Switzerland

e-mail: cschmitz@ems-ch.com

C. Schmitz $\cdot$ R. DePace

Electro Medical Systems Corporation, 11886 Greenville Ave., Ste. 120, Dallas, TX 75243, USA unwanted side effects such as arterial embolisms or even severe damage of the lung.

Our major concern, however, is linked to Section "Associative memory model for establishing reflex functions" of Dr. Wess' article [1]. This section outlines in one and half pages, a hypothesis of so-called "associative pain memory", without so much as a reference to the literature. An essential part of this model is the idea of separating pain from pathology, as expressed in the following sentences by Dr. Wess [1]:

- "Chronic pain, for example, without underlying anatomical disorders is considered a pathological control function" (p. 328, right column, lines $12 \mathrm{ff}$ );

- "In cases of chronic pain without organic reasons [...]" (p. 329, right column, line 24); and

- "Therapeutic treatment modalities are no more focused on specific organs under pain but on pain memory" (p. 329, right column, lines $33 \mathrm{ff}$ ).

Further, in Section "Hypothetic mechanism of shock wave therapy" Dr. Wess writes [1]:

- "The problem seems to be too complex for a simple answer since the location of the pathology is considered not in the painful organ itself anymore but is diffusely spread over extended areas as well as over several levels of the PNS/CNS." (peripheral nervous system/central nervous system) (p. 331, right column, lines $7 \mathrm{ff}$ ).

In this regard, the following questions arise:

1. Is this really the field of ESWT, i.e., are users of ESWT really treating "pain without underlying anatomical disorders", and are they "no more focused on specific organs under pain but on pain memory"?

2. Are molecular and cellular mechanisms known as to how extracorporeal shock waves might mediate their 
pain-relieving action on anatomical disorders of the musculoskeletal system?

3. If users of ESWT are treating anatomically defined disorders and the potential underlying molecular and cellular mechanisms are known, what might have been Dr. Wess' [1] motivation to publish his hypothesis without reference to this knowledge?

It is beyond the scope of this letter to provide comprehensive answers to these questions. However, the following appears essential:

1. ESWT is not used in the international peer-reviewed literature to treat "pain without underlying anatomical disorders", and ESWT cannot be regarded "no more focused on specific organs under pain but on pain memory". This can be deduced easily from the titles of recent prospective, randomized, controlled clinical trials using ESWT published in the international peerreviewed literature, such as:

- "Radial extracorporeal shock wave therapy is safe and effective in the treatment of chronic recalcitrant plantar fasciitis: results of a confirmatory randomized placebo-controlled multicenter study." [3];

- "Eccentric loading, shock wave treatment, or a waitand-see policy for tendinopathy of the main body of tendo Achillis: a randomized controlled trial." [4]; and

- "A randomized controlled trial of extracorporeal shock wave therapy for lateral epicondylitis (tennis elbow)." [9].

Note that these indications are anatomically defined diseases of attachment sites ("entheses") where tendons and ligaments meet bone, i.e., regions with a very specific pathology and pathophysiology [12].

2. Several molecular and cellular mechanisms were reported recently on how extracorporeal shock waves might mediate their pain-relieving action (again, reference was made to specific titles of studies published in the international peer-reviewed literature):

- "Substance P and prostaglandin E2 release after shock wave application to the rabbit femur." [13];

- "Extracorporeal shockwave application to the distal femur of rabbits diminishes the number of neurons immunoreactive for substance $\mathrm{P}$ in dorsal root ganglia L5." [14];

- "Application of shock waves to rat skin decreases calcitonin gene-related peptide (CGRP) immunoreactivity in dorsal root ganglion neurons." [15]; and

- "Selective loss of unmyelinated nerve fibers after extracorporeal shockwave application to the musculoskeletal system." [16].
Substance $\mathrm{P}$ is concentrated in unmyelinated C-fibers and a subpopulation of slowly conducting, lightly myelinated A- $\delta$ nerve fibers, and is released at central and peripheral terminals of sensory nociceptive neurons after stimulation [1719]. CGRP is a marker of sensory neurons typically involved with pain perception and was immunohistochemically co-localized with substance $P$ in capsaicin-sensitive axons [20]. Activation of peripheral small diameter sensory neurons by local depolarization, axonal reflexes or dorsal root reflexes releases substance $\mathrm{P}$ and CGRP. Both substances then act on target cells in the periphery such as mast cells, immune cells and vascular smooth muscle cells, thus producing inflammation. This phenomenon is called neurogenic inflammation, and is, an inflammatory symptom that results from the release of substances from primary sensory nerve terminals [21, 22]. Evidence has emerged that chronic inflammation contributes to the etiology of pain in tennis elbow and chronic plantar fasciitis [23-27]. Furthermore, a recent study revealed the contribution of substance $\mathrm{P}$ (as well as interleukin 1 alpha and transforming growth factor beta1) in the pathogenesis of tennis elbow, without apparent infiltration of inflammatory cells [28]. Moreover, depletion of substance $\mathrm{P}$ was shown repeatedly to reduce experimentally induced inflammation of paws and joints in laboratory animals [29-31]. It is therefore reasonable to hypothesize that (1) neurogenic inflammation plays an important role in the pathogenesis of tennis elbow and chronic plantar fasciitis, and (2) reduction of substance $P$ in the target tissue [13] in conjunction with reduced synthesis of this molecule in dorsal root ganglia cells [14] plays an important role in ESWT-mediated long-term analgesia in the treatment of these diseases. Selective destruction of unmyelinated nerve fibers within the focal zone of the shock waves [16] might also contribute to this analgesia. Also important to mention is that unmyelinated C-fibers are known to be responsible for throbbing, chronic pain [32].

3. One can only speculate as to Dr. Wess' motivation to publish his hypothesis [1] without any reference to the detailed knowledge existing in the international peerreviewed literature outlined above. An interesting indication in this regard might emerge from the fact that Dr. Wess is affiliated with Storz Medical AG (Tägerwillen, Switzerland), the manufacturer of several extracorporeal shock wave systems (among them the D-ACTOR 200 marketed in the USA [33]). The US Food and Drug Administration (FDA) classifies extracorporeal shock wave therapy devices as Class III, highest risk devices. According to FDA, the risk the type of device poses to the patient or the user is a major factor in the class it is assigned [34]. Approval of a Class III device requires demonstration of clinical efficacy and safety in a so-called "investigational 
device exemption" (IDE) study. Based on the results of this study, FDA then grants "pre-market approval" (PMA) to the manufacturer to market the device in the US marketplace.

To date (25 February 2009), the following extracorporeal shock wave devices have been granted PMA by FDA:

- OssaTron (HealthTronics, Inc., Marietta, GA, USA); PMA no. P990086 issued on 12 October 2000 to treat chronic heel pain [35];

- Dornier Epos Ultra (Dornier Medical Systems, Inc., Kennesaw, GA, USA); PMA no. P000048 issued on 15 January 2001 for treatment of chronic plantar fasciitis for patients with symptoms of plantar fasciitis for 6 months or more and a history of unsuccessful conservative therapy [36];

- Siemens SONOCUR Basic (Siemens Medical Solutions, Inc., Iselin, NJ, USA); PMA no. P010039 issued on 19 July 2002 for treatment for pain due to tennis elbow [37];

- Orthospec Extracorporeal Shock Wave Therapy (Medispec, Ltd; Germantown, MD, USA); PMA no. P040026 issued 1 April 2005 for treatment of proximal plantar fasciitis with or without heel spur in patients 18 years of age or older [38];

- Orbasone Pain Relief System (Orthometrix, Inc., White Plains, NY, USA); PMA no. P040039 issued on 10 August 2005 to relieve heel pain (proximal plantar fasciitis) [39]; and

- EMS Swiss DolorClast (EMS Electro Medical Systems, Nyon Switzerland); PMA no. P050004 issued on 8 May 2007 to treat heel pain associated with chronic proximal plantar fasciitis [40].

In contrast, the extracorporeal shock wave system D-ACTOR 200 has been presented to FDA as Class I medical device, predicated on a similar function and purpose to "Therapeutic Massagers" (Regulation Number 890.5660 within Title 21 of the Code of Federal Regulations (CFR) [41]. As a result, the D-ACTOR has been granted 510[k] Premarket Notification by FDA as a Class I "Massager, Therapeutic, Electric" (510[k] no. K072809; decision date 27 June 2008) [42]. It remains unknown whether clinical efficacy and safety of ESWT treatment with the D-ACTOR 200 has been demonstrated in an IDE study; corresponding data has not been published in the international peerreviewed literature. Note that $510[\mathrm{k}]$ Premarket Notification of Class I devices usually does not require a medical device manufacturer to perform an IDE study and present the results to FDA. The reason for this is that FDA considers Class I submissions as "lowest risk" devices that may bypass the lengthy and costly trials needed to enter the US marketplace. Examples of Class I medical devices include: tongue depressors, elastic bandages, reading glasses and forceps [34].
Appendix G of the 510(k) Premarket Notification of the D-ACTOR 200 indicates that this medical device is intended for the following: (2) to relieve minor muscle aches and pains, and (2) for the temporary increase in local blood circulation [42]. This is in striking contrast to all other extracorporeal shock wave devices listed above whose use is clearly intended for treating pain associated with anatomically defined disorders. The latter, however, is not the purpose of Therapeutic Massagers regulated by FDA under Regulation Number 890.5660 within CFR Title 21 [41]. In other words, FDA has not specified that Therapeutic Massagers may be used for the treatment of the anatomically defined diseases as discussed in this letter. This is also in line with the fact that no evidence exists in the international peer-reviewed literature that Therapeutic Massagers exert their biomedical actions on the musculoskeletal system by the molecular and cellular mechanisms outlined above. Rather, anatomically defined diseases such as chronic plantar fasciitis and chronic Achilles tendinopathy are discussed in the current international peer-reviewed literature as potential indications for treatment with extracorporeal shock waves but not with Therapeutic Massagers [43, 44].

In summary, the modern concept of ESWT for various indications of the musculoskeletal system is based on the principles of molecular cell biology and clinical evidence based medicine, witnessed by numerous publications in the international peer-reviewed literature. Dr. Wess' hypothesis [1] does not refer to this knowledge and should be evaluated cautiously against the fact that the extracorporeal shock wave system D-ACTOR 200 manufactured by Storz Medical AG (Dr. Wess' affiliation) has not been presented to FDA as a Class III extracorporeal shock wave device but rather as Class I device, being similar in function and purpose to Therapeutic Massagers.

Open Access This article is distributed under the terms of the Creative Commons Attribution Noncommercial License which permits any noncommercial use, distribution, and reproduction in any medium, provided the original author(s) and source are credited.

\section{References}

1. Wess OJ (2008) A neural model for chronic pain and pain relief by extracorporeal shock wave treatment. Urol Res 36:327-334. doi:10.1007/s00240-008-0156-2

2. Rompe JD, Furia J, Weil L, Maffulli N (2007) Shock wave therapy for chronic plantar fasciopathy. Br Med Bull 81-82:183-208. doi:10.1093/bmb/ldm005

3. Gerdesmeyer L, Frey C, Vester J, Maier M, Weil L Jr, Weil L Sr, Russlies M, Stienstra J, Scurran B, Fedder K, Diehl P, Lohrer H, Henne M, Gollwitzer H (2008) Radial extracorporeal shock wave therapy is safe and effective in the treatment of chronic recalcitrant plantar fasciitis: results of a confirmatory 
randomized placebo-controlled multicenter study. Am J Sports Med 36:2100-2109. doi:10.1177/0363546508324176

4. Rompe JD, Nafe B, Furia JP, Maffulli N (2007) Eccentric loading, shock-wave treatment, or a wait-and-see policy for tendinopathy of the main body of tendo Achillis: a randomized controlled trial. Am J Sports Med 35:374-383. doi:10.1177/0363546506295940

5. Rompe JD, Furia J, Maffulli N (2008) Eccentric loading compared with shock wave treatment for chronic insertional achilles tendinopathy. A randomized, controlled trial. J Bone Joint Surg Am 90:52-61. doi:10.2106/JBJS.F.01494

6. Rompe JD, Furia J, Maffulli N (2009) Eccentric loading versus eccentric loading plus shock-wave treatment for midportion achilles tendinopathy: a randomized controlled trial. Am J Sports Med 37(3):463-470

7. Spacca G, Necozione S, Cacchio A (2005) Radial shock wave therapy for lateral epicondylitis: a prospective randomised controlled single-blind study. Eura Medicophys 41:17-25

8. Rompe JD, Maffulli N (2007) Repetitive shock wave therapy for lateral elbow tendinopathy (tennis elbow): a systematic and qualitative analysis. Br Med Bull 83:355-378. doi:10.1093/bmb/ $\operatorname{ldm} 019$

9. Staples MP, Forbes A, Ptasznik R, Gordon J, Buchbinder R (2008) A randomized controlled trial of extracorporeal shock wave therapy for lateral epicondylitis (tennis elbow). J Rheumatol 35:20382046

10. Khattab AA, Brodersen B, Schuermann-Kuchenbrandt D, Beurich H, Tölg R, Geist V, Schäfer T, Richardt G (2007) Extracorporeal cardiac shock wave therapy: first experience in the everyday practice for treatment of chronic refractory angina pectoris. Int $\mathbf{J}$ Cardiol 121:84-85. doi:10.1016/j.ijcard.2006.08.030

11. Zimmermann R, Cumpanas A, Hoeltl L, Janetschek G, Stenzl A, Miclea F (2008) Extracorporeal shock-wave therapy for treating chronic pelvic pain syndrome: a feasibility study and the first clinical results. BJU Int 102:976-980. doi:10.1111/j.1464410X.2008.07742.X

12. Benjamin M, Toumi H, Ralphs JR, Bydder G, Best TM, Milz S (2006) Where tendons and ligaments meet bone: attachment sites ('entheses') in relation to exercise and/or mechanical load. J Anat 208:471-490. doi:10.1111/j.1469-7580.2006.00540.x

13. Maier M, Averbeck B, Milz S, Refior HJ, Schmitz C (2003) Substance $\mathrm{P}$ and prostaglandin $\mathrm{E} 2$ release after shock wave application to the rabbit femur. Clin Orthop Relat Res (406):237-245. doi:10.1097/00003086-200301000-00034

14. Hausdorf J, Lemmens MA, Kaplan S, Marangoz C, Milz S, Odaci E, Korr H, Schmitz C, Maier M (2008) Extracorporeal shockwave application to the distal femur of rabbits diminishes the number of neurons immunoreactive for substance $\mathrm{P}$ in dorsal root ganglia L5. Brain Res 1207:96-101. doi:10.1016/j.brainres.2008.02.013

15. Takahashi N, Wada Y, Ohtori S, Saisu T, Moriya H (2003) Application of shock waves to rat skin decreases calcitonin gene-related peptide immunoreactivity in dorsal root ganglion neurons. Auton Neurosci 107:81-84. doi:10.1016/S1566-0702(03)00134-6

16. Hausdorf J, Lemmens MA, Heck KD, Grolms N, Korr H, Kertschanska S, Steinbusch HW, Schmitz C, Maier M (2008) Selective loss of unmyelinated nerve fibers after extracorporeal shockwave application to the musculoskeletal system. Neuroscience 155:138-144. doi:10.1016/j.neuroscience.2008.03.062

17. Keen P, Harmar AJ, Spears F, Winter E (1982) Biosynthesis, axonal transport and turnover of neuronal substance P. Ciba Found Symp 91:145-164

18. Malcangio M, Bowery NG (1999) Peptide autoreceptors: does an autoreceptor for substance P exist? Trends Pharmacol Sci 20:405407. doi:10.1016/S0165-6147(99)01388-7
19. Snijdelaar DG, Dirksen R, Slappendel R, Crul BJ (2000) Substance P. Eur J Pain 4:121-135. doi:10.1053/eujp.2000.0171

20. Gibbins IL, Furness JB, Costa M, MacIntyre I, Hillyard CJ, Girgis S (1985) Co-localization of calcitonin gene-related peptide-like immunoreactivity with substance $P$ in cutaneous, vascular and visceral sensory neurons of guinea pigs. Neurosci Lett 57:125-130. doi:10.1016/0304-3940(85)90050-3

21. Holzer P (1988) Local effector functions of capsaicin-sensitive sensory nerve endings: involvement of tachykinins, calcitonin gene-related peptide and other neuropeptides. Neuroscience 24:739-768. doi:10.1016/0306-4522(88)90064-4

22. Richardson JD, Vasko MR (2002) Cellular mechanisms of neurogenic inflammation. J Pharmacol Exp Ther 302:839-845. doi:10.1124/jpet.102.032797

23. Nirschl RP (1977) Tennis elbow. Prim Care 4:367-382

24. Kamien M (1990) A rational management of tennis elbow. Sports Med 9:173-191. doi:10.2165/00007256-199009030-00005

25. LeMelle DP, Kisilewicz P, Janis LR (1990) Chronic plantar fascial inflammation and fibrosis. Clin Podiatr Med Surg 7:385-389

26. Schepsis AA, Leach RE, Gorzyca J (1991) Plantar fasciitis. Etiology, treatment, surgical results, and review of the literature. Clin Orthop Relat Res (266):185-196

27. Roetert EP, Brody H, Dillman CJ, Groppel JL, Schultheis JM (1995) The biomechanics of tennis elbow. An integrated approach. Clin Sports Med 14:47-57

28. Uchio Y, Ochi M, Ryoke K, Sakai Y, Ito Y, Kuwata S (2002) Expression of neuropeptides and cytokines at the extensor carpi radialis brevis muscle origin. J Shoulder Elbow Surg 11:570-575. doi: $10.1067 / \mathrm{mse} .2002 .126769$

29. Lam FY, Ferrell WR (1991) Neurogenic component of different models of acute inflammation in the rat knee joint. Ann Rheum Dis 50:747-751. doi:10.1136/ard.50.11.747

30. Cruwys SC, Garrett NE, Kidd BL (1995) Sensory denervation with capsaicin attenuates inflammation and nociception in arthritic rats. Neurosci Lett 193:205-207. doi:10.1016/03043940(95)11704-Z

31. Garrett NE, Cruwys SC, Kidd BL, Tomlinson DR (1997) Effect of capsaicin on substance $\mathrm{P}$ and nerve growth factor in adjuvant arthritic rats. Neurosci Lett 230:5-8. doi:10.1016/S0304-3940(97) 00458-8

32. Kandel ER, Schwartz JH, Jessell TM (2000) Principles of neural science, 4th edn. McGraw-Hill, Columbus

33. Storz Medical. System Book D-ACTOR 200, p. 3

34. United States Government Accountability Office (2009) FDA should take steps to ensure that high-risk device types are approved through the most stringent premarket review process. Report GAO-09-190 to Congressional Addressees, January 2009

35. http://www.fda.gov/cdrh/pdf/P990086.html

36. http://www.fda.gov/cdrh/pdf/p000048.html

37. http://www.fda.gov/cdrh/pdf/P010039.html

38. http://www.fda.gov/cdrh/pdf4/p040026.html

39. http://www.fda.gov/cdrh/pdf4/p040039.html

40. http://www.fda.gov/cdrh/mda/docs/P050004.html

41. http://www.accessdata.fda.gov/SCRIPTs/cdrh/cfdocs/cfcfr/ CFRSearch.cfm?fr $=890.5660$

42. http://www.fda.gov/cdrh/pdf7/K072809.pdf

43. Alfredson H, Cook J (2007) A treatment algorithm for managing Achilles tendinopathy: new treatment options. Br J Sports Med 41:211-216. doi:10.1136/bjsm.2007.035543

44. Neufeld SK, Cerrato R (2008) Plantar fasciitis: evaluation and treatment. J Am Acad Orthop Surg 16:338-346 